\title{
PENGEBORAN LEPAS PANTAI
}

\author{
Budi Utomo \\ Program Diploma III Teknik Perkapalan \\ Fakultas Teknik Universitas Diponegoro
}

\begin{abstract}
Budi Utomo, in this paper explain that offshore drilling carried out to obtain crude oil through the oil wells. The means that must exist in the operation of offshore drilling is a bridge structure (plate form) as a place to put the drilling equipment. Known two kinds of platforms, that is platforms permanent (fixed) which stands on the feet of reinforced concrete, and the bridge is not fixed like swamp barges, drilling ship (floaters) and jack-up rig.

Jack up rig is one of the offshore rigs that have the ability to elevation in accordance with a sea depth of drilling. Drilling equipment is a range of equipment that is prepared in such a way, so that such a drill rod, and all this equipment has a hole inside that allows for fluid or mud circulation.
\end{abstract}

Key word: Drilling equipment

\section{PENDAHULUAN}

Bahan bakar minyak di Indonesia merupakan salah satu produk yang banyak dibutuhkan oleh masyarakat, dengan bertambahnya jumlah penduduk maka konsumsi bahan bakar minyak yang dibutuhkan semakin meningkat.

Pada umumnya minyak bumi ditemukan di daerah-daerah terpencil yang tidak dihuni atau sukar didatangi oleh manusia, seperti di hutan rimba, rawarawa, padang pasir dan daerah perairan atau lepas pantai.

Dari wilayah yang terpencil itu minyak mentah di dapatkan melalui sumur minyak hasil dari pengeboran dan selanjutnya minyak mentah dialirkan ke kilang minyak untuk diolah menjadi produk yang berguna seperti bensin, kerosin, minyak diesel dan lain-lain.

Pada sistem pengeboran lepas pantai memiliki sistem yang tidak jauh berbeda dengan sistem yang ada didarat, karena kondisi lingkungan darat dan laut sangat berbeda maka metode operasi pengeboran lepas pantai membutuhkan teknologi yang baru dan biaya operasi yang mahal.

Peralatan mutlak yang harus ada dalam operasi pengeboran lepas pantai adalah sebuah strutur anjungan (platform) sebagai tempat untuk meletakkan peralatan pemboran dan produksi. Sekarang ini berbagai macam anjungan telah dibuat, seperti anjungan permanen (fixed) yang berdiri diatas kakikaki beton bertulang. Jenis ini umumnya digunakan pada laut dangkal dan pada lapangan pengembangan sehingga dapat sekaligus menjadi anjungan pemboran dan produksi

Ada berbagai hambatan alam yang harus diatasi saat pengoperasian unit lepas pantai. Hambatan tersebut antara lain : angin, ombak, arus dan badai. Khusus untuk unit terapung yang amat peka terhadap pengaruh kondisi laut, maka harus disediakan peralatan khusus, yaitu peralatan peredam gerak oscilsi vertikal akibat ombak dan peralatan pengendalian posisi pada unit terapung. Untuk pengendalian posisi pada unit terapung dikenal dengan mooring system dan sistem pengendalian posisi dinamik . Sedangkan untuk mengatasi gerak vertikal keatas dan kebawah umumnya digunakan Drill String Compensator (DSC).

\section{DASAR TEORI}

Operasi pengeboran lepas pantai dimulai dari pengembangan teknologi pengeboran darat dengan menggunakan casing conduktor yang ditanam atau dibor dan disemen, kemudian meningkat dengan digunakan mud-line suspention system, dan terus meningkat dengan menggunakan riser system. Penggunaan BOP (blow Out Preventive) konventional terus dimodifikasi agar mampu beroperasi di bawah air. Kondisi lingkungan laut berpengaruh terhadap pemilihan jenis platform yang digunakan.

Dalam operasinya pengeboran lepas pantai membutuhkan sarana utama pengeboran yaitu berupa kendaraan atau disebut Drilling rig. Pengeboran lepas pantai bisa dilakukan dengan 3 jenis kendaraan atau drilling rig, hal tersebut tergantung pada kedalaman air di tempat yang akan dilakukan proses pengeboran/lokasi pengeboran, jenis driiling rig tersebut antara lain adalah:

- Swamp Barge

Merupakan driiling rig yang digunakan untuk kedalaman 7 - $15 \mathrm{ft}$ (laut dangkal) Cara kerjanya adalah dengan memobilisasi rig ke lokasi sumur, kemudian rig ditenggelamkan dengan cara mengisi ballast tanknya dengan air. Setelah rig duduk di dasar dan spud cannya tertanam di dasar laut, baru proses pengeboran bisa dimulai. Untuk mencegah 
rig terdesak arus laut yang terkadang kuat, biasanya posisi rig distabilkan dulu dengan cara mengikatkan rig pada tiang - tiang pancang di sekitarnya, karena apabila tidak stabil dan posisi rig tergeser oleh arus, hal ini bisa menjadi masalah yang serius. Swamp Barge ditunjukkan pada Gambar.1.

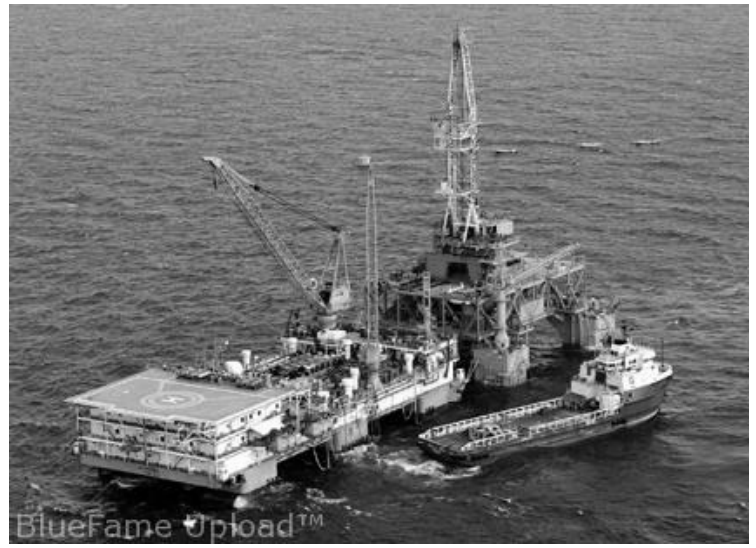

Gambar 1. Swamp Barge (Tender Barge Rig)

\section{- Drillships (floater)}

Untuk laut dalam (>250 ft), digunakan drillships (floater) atau semi-submersible. Drilling rig tipe floaters biasanya dipakai untuk mengebor sumursumur explorasi karena praktis rig jenis ini tidak bisa melekat pada platform untuk mengebor sumursumur development. Rig jenis ini, biasanya dilengkapi dengan 8 anchor/jangkar, yang tersebar di sekeliling rig.

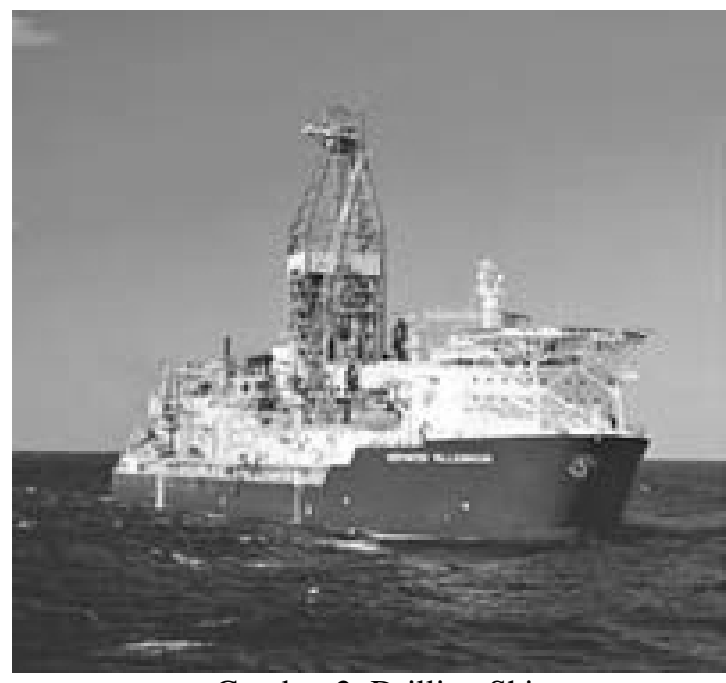

Gambar 2. Drilling Ship

- Jack-up rig

Digunakan untuk kedalaman 15 - $250 \mathrm{ft}$, jack-up rig biasanya berkaki 3 atau 4, dan ada yang tipe independent legs dengan spud can di masing - masing leg atau ada juga yang non-independent leg dengan tipe "mat foundation" seperti fondasi telapak. Kaki rig dengan tipe mat foundation ini biasanya dipakai di kawasan laut yang mempunyai soft seabed (dasar laut yang lembut sehingga dengan kaki rig tipe mat tertanam tidak terlalu dalam). Rig tipe jack up bisa digunakan untuk mengebor sumur - sumur explorasi maupun development (pengembangan). Jackup rig adalah platform yang dapat mengapung dan mempunyai tiga atau empat kaki yang dapat dinaik-turunkan. Untuk dapat dioperasikan, semua kakinya harus diturunkan sampai menginjak dasar laut. Kemudian badan rig akan diangkat sampai di atas permukaan air sehingga bentuknya menjadi semacam platform tetap. Untuk berpindah dari satu tempat ke tempat lain, semua kakinya haruslah dinaikan terlebih dahulu sehingga badan rig mengapung di atas permukaan air. Lalu rig ini ditarik menggunakan beberapa kapal tarik ke lokasi yang dituju. Kedalaman operasi jackup rig adalah antara $5 \mathrm{~m}$ sampai 200m. Jack up rig merupakan salah satu offshore rig yang mempunyai kemampuan untuk berelevasi sesuai dengan kedalaman laut tempat dia malakukan pengeboran. Ciri utama rig ini adalah adanya menara yang terbuat dari baja yang digunakan untuk menaik-turunkan pipa-pipa tubular sumur. Dengan tiga atau ada juga yang empat kaki yang dimiliki maka Jack Up Rig mempunyai tingkat kestabilan dalam operasi yang tinggi dibandingkan dengan offshore drilling yang lain seperti drill ship, semisubmersible, barge drilling, dll. Jack up rig pada umumnya terdiri atas lima lantai :

o Main deck berhubungan dengan lantai utama di mana terdapat fasilitas-fasilitas umum seperti ruang makan, ruang rekreasi, dan poliklinik.

o Di bawah lantai utama adalah pusat utilitas. Di sini terdapat generator untuk mensuplai seluruh kebutuhan listrik. Terdapat juga mesin penggerak utama kapal yang biasa dipakai waktu berlayar, juga terdapat tempat untuk pengolahan air untuk memenuhi kebutuhan air tawar yang diperoleh dari penyulingan air laut.

o Di atas lantai utama adalah lantai satu. Di sini terdapat kamar-kamar tidur yang dilengkapi juga dengan kamar mandi. Hampir seluruh pekerja tidur di lantai satu ini.

o Di atas lantai satu adalah lantai dua. Di sini ruangan kantor utama berada, tempat staff pimpinan dan karyawan biasa melakukan meeting. Di sini juga tempat kegiatan-kegiatan administrasi dilakukan sehingga ruangan ini dilengkapi dengan mesin fax, fotocopy, telepon dan komputer . 
o Lantai tiga adalah tempat nahkoda kapal bekerja. Di mana seluruh kegiatan dapat dipantau. Di lantai tiga ini juga terdapat halipad yang memungkinkan untuk didarati halikopter dalam kondisi darurat.

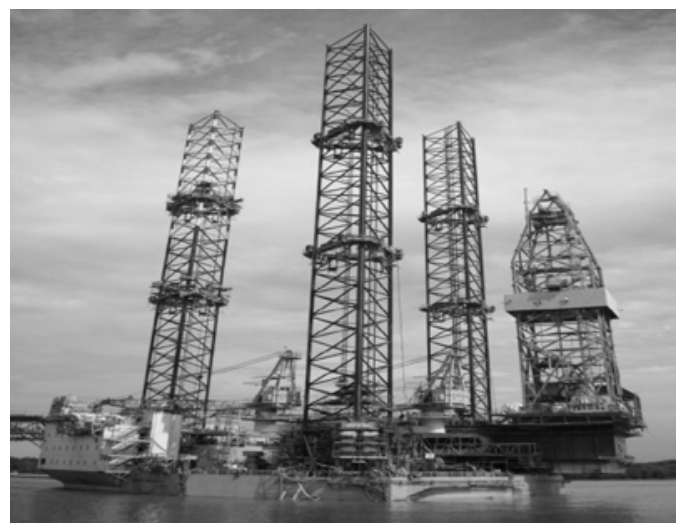

Gambar 3. Jack Up Rig

Jack up memiliki Struktur utama/main structure yang penting dalam melakukan operasinya. Main structure yang terdapat pada jack up adalah :

o Leg : cylindrical atau trussed

o Spudcan : Sepatu leg yang nantinya akan masuk dan menyentuh sea bed sebagai pondasi jack up.

o Cantilever : Tempat drilling dioperasikan, dapat bergerak kearah $\mathrm{X}$ and $\mathrm{Y}$

o Hull : berisi beberapa tanki yang disesuaikan dengan kebutuhan dan compartment untuk memasang beberpa equiptment dan machinery untuk drilling operation.

o Accomodation atau living quarter dimana para pekerja akan bekerja dan tempat istirahat dengan berbagai macam fasilitas.

o Helli deck : Deck untuk menempatkan halikopter.

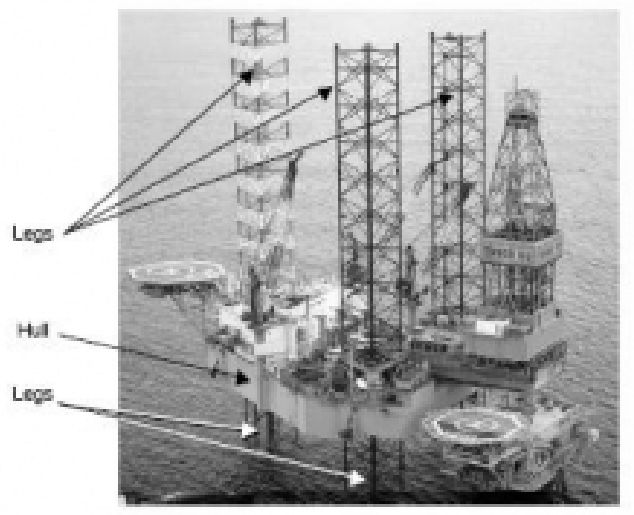

Gambar 4. Struktur Jack Up Rig

\section{PEMBAHASAN}

Pengeboran lepas pantai terdiri atas serangkaian sistim peralatan pengeboran, diantaranya adalah drilling string atau sering disebut rangkaian pengeboran, yaitu serangkaian peralatan yang disusun sedemikian rupa, sehingga membentuk batang bor, seluruh peralatan ini mempunyai lubang dibagian dalamnya yang memungkinkan untuk melakukan sirkulasi fluida atau mud. Bagian ujung terbawah dari rangkaian pemboran adalah pahat bor atau bit yang gunanya untuk mengorek atau menggerus batuan, sehingga lubang bor bertambah dalam.

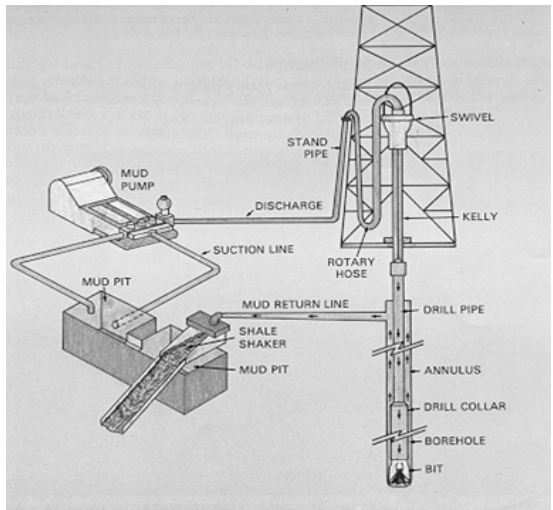

Gambar 5. Drilling string

Diatas pahat bor disambung dengan beberapa buah drill colar, yaitu pipa penyambung terdalam susunan rangkaian pemboran, untuk memungkinkan pencapain kedalaman tertentu, makin dalam lubang bor makin banyak jumlah drill pipe yang dibutuhkan. Diatas drill pipe disambung dengan pipa kelly, yang bertugas meneruskan gerakan dari rotary table untuk memutar seluruh rangkaian pengeboran.

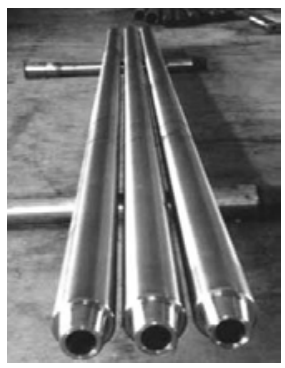

Gambar 6. Drill Pipe

Diatas kelly disambung dengan swivel yaitu sebuah alat yang berfungsi sebagai tempat perpindahan gerakan putar dan gerakan diam dari sistem sirkulasi, fluida pemboran melalui pipa bertekanan tinggi, bagian atas dari kelly terdapat bail untuk dikaitkan ke hook supaya memungkinkan turun ke seluruh rangkaian pemboran. 
Selain drilling string yg merupakan salah satu peralatan pengeboran juga terdapat peralatan peralatan lain yg dibutuhkan untuk melaksanakan proses pengeboran pada Offshore.
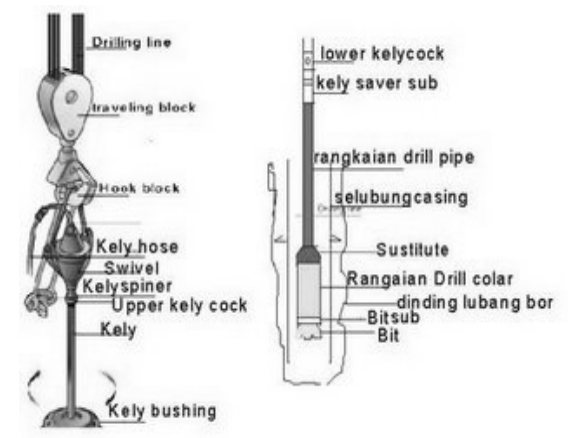

Gambar 7. Peralatan Pengeboran

Peralatan lain tersebut diantaranya adalah:

- Bit Sub

Merupakan bagian ujung terbawah dari rangkaian pengboran, bit sub adalah pahat bor atau bit yang gunanya untuk mengorek atau menggerus batuan, sehingga lubang bor bertambah dalam. Diatas pahat bor disambung dengan beberapa buah drill colar, yaitu pipa penyambung terdalam susunan rangkaian pengeboran, untuk memungkinkan pencapain kedalaman tertentu, makin dalam lubang bor makin banyak jumlah drill pipe yang dibutuhkan

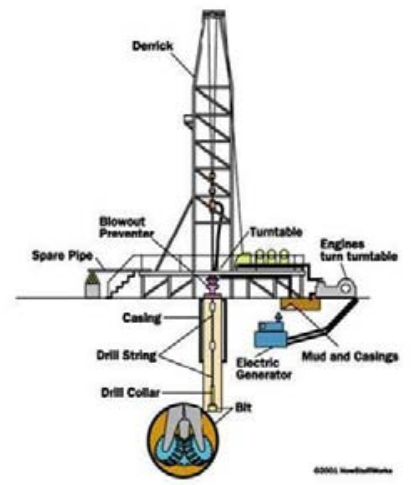

Gambar 8. Bit sub

\section{- Float Sub}

Adalah sub penyambung yang dipasang bit sub dan drill colar, berfungsi untuk menutup semburan /tekanan formasi kedalam rangkaian pemboran secara otomatis. Float Sub ditunjukkan seperti Gambar .9.

\section{- Stabilizer}

Adalah alat yang dipasang pada susunan drill colar, yang berfungsi untuk menstabilkan arah lubang bor dan mengurangi kemungkinan terjepitnya rangkaian pengeboran yang diakibatkan oleh differensial pressure.

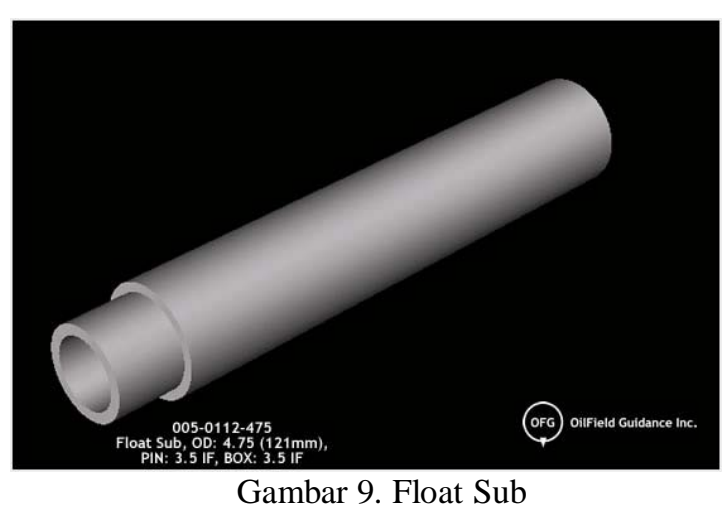

Stabilizer digunakan sebagai bottom hole assembly untuk menjaga kestabilan bit dan drill collar dalam lubang bor selama berlangsung operasi pengeboran. Pada umumnya stabilizer di gunakan untuk tujuan sebagai berikut :

o Untuk meningkatkan penembusan (increased penetration). Stabilizer akan memberikan WOB (Weight of Bit) yang lebih besar pada drill collar sehingga meningkatkan laju pemboran (penetration rate)

o Untuk memperkecil kemungkinan terjadinya patah lelah (fatique) pada sambungan drill collar.

o Untuk mencegah terjadinya well sticking. Stabilizer dapat menahan permukaan rangkaian pipa bor tetap tidak menyentuh dinding lubang bor.

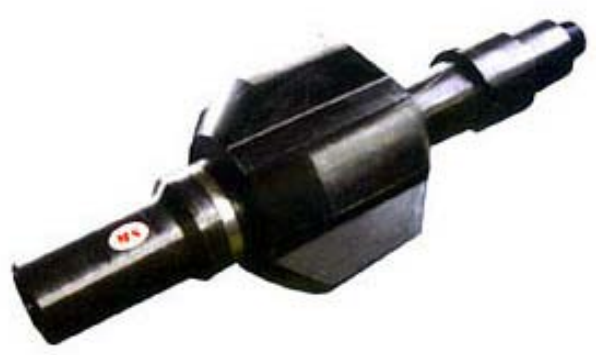

Gambar 10. Stabilizer

- Kelly saver sub

yaitu alat yang dipasang dibagian ujung bawah kelly, berfungsi untuk melindungi ulir kelly agar tidak cepat rusak. Kelly merupakan rangkaian pipa bor yang paling atas dimana bentuk irisan luarnya dapat berbentuk segitiga, segiempat, segienam. Kelly ini dimasukkan ke dalam kelly bushing. Kelly bushing berfungsi untuk meneruskan gaya putar (torsi) dari meja putar ke kelly dan selanjutnya keseluruh rangkaian pipa bor. Selama kelly ini tidak dipergunakan (dilepas) misal pada waktu mencabut string, maka kelly ini dimasukkan ke dalam rathole yang terdapat di lantai bor. Dalam keadaan ini kelly 
bushing selalu ikut terbawa demikian pula swivelnya.

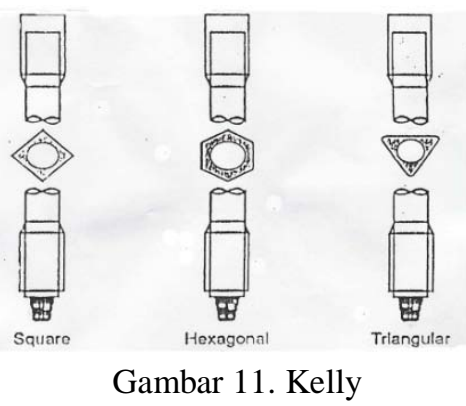

Kelly adalah suatu pipa baja yang sangat kuat dan tebal, badanya berbentuk segi-segi, memungkinkan dapat diangkat naik turun dan diputar oleh rotary table. Fungsi dari kelly adalah :

o Penghubung antara swivel dan rangkaian pemboran untuk dapat menaikan, menurunkan, dan memutar

o Meneruskan tenaga gerak putar dari rotari table ke rangkaian pemboran

o Memungkinkan rangkaian pemboran bergerak turun sambil berputar selama pemboran.

o Sebagai sarana penerus aliran sirkulasi cairan pemboran atau fluida dari swivel menuju ke rangkaian dibawahnya.

\section{- Lower kelly cock}

Adalah alat yang dipasang antara kelly dan kelly saver sub, befungsi untuk alat penutup semburan /tekanan dari dalam pipa pada saat posisi kelly diatas rotary table. Lower kelly cock disebut juga kelly valve, dipasang di bawah kelly dan dipakai bila upper kelly cock rusak dan adakalanya untuk mencegah lumpur dari kelly berjatuhan saat melepas kelly.

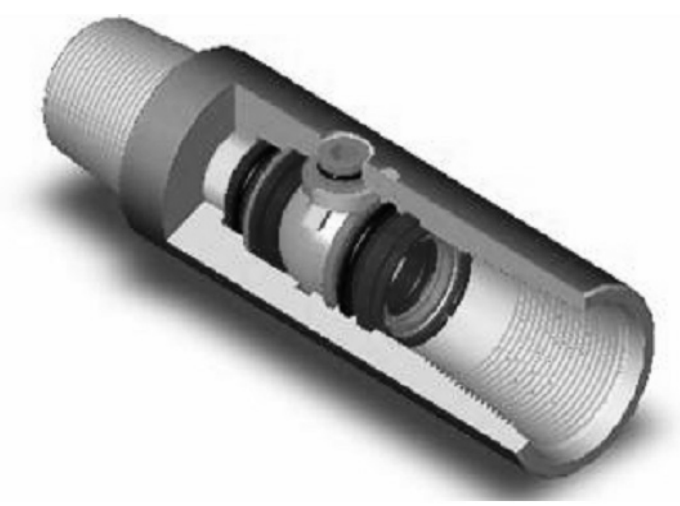

Gambar 12. Lower kelly cock
- Upper Kelly Cock

Adalah alat yang dipasang diantara kelly dan swivel, berfungsi untuk menutup semburan/tekanan dari dalam pipa saat kelly down. Upper kelly cock disebut juga upper kelly valve atau disebut kelly cock saja. Ia dipasang diantara kelly joint dan swivel dan memiliki ulir kiri. Fungsi dari kelly cock adalah untuk mengisolasi lumpur dari drill stem dengan swivel, rotary hose dan stand pipe bila terjadi kebocoran atau untuk mencegah pecahnya peralatan tersebut karena tekanan dari sumur yang tinggi. Dengan adanya kelly cock memungkinkan untuk mereparasi dan mengganti peralatan di swivel dan lain-lain pada saat sumur ada tekanan atau sedang terjad kick. Kelly cock harus memiliki tekanan kerja sama atau lebih besar dari blowout preventer yang dipakai dan harus mempunyai diameter pembukaan sama dengan kelly. Kelly cock umumnya tersedia dengan tekanan kerja 5.000 dan 10.000 Psi dan mampu menahan berat string. Untuk mengoperasikan kelly cock diperlukan wrench (kunci) tertentu dan disarankan dioperasikan buka tutup dan diuji secara periodik untuk mencegah kemacetan dan kebocoran.

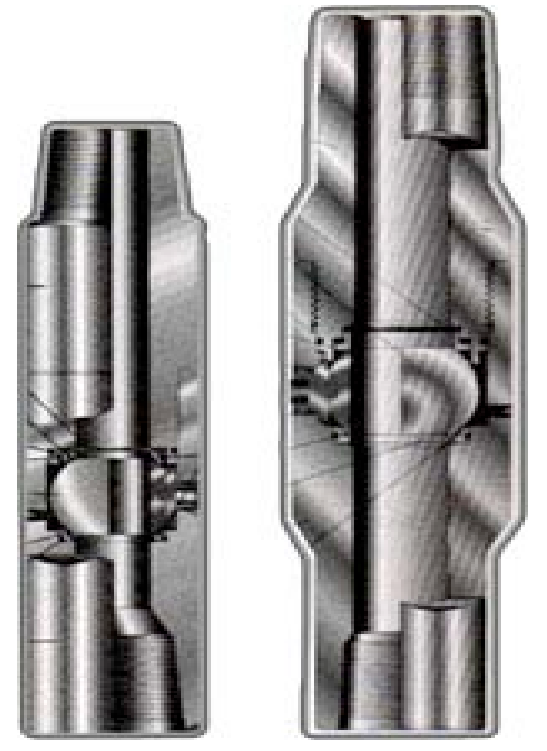

Gambar 13. Upper Kelly Cock

\section{KESIMPULAN}

Pengeboran lepas pantai dilakukan untuk mendapatkan minyak mentah melalui sumur minyak. Sarana yang harus ada dalam operasi pemboran lepas pantai adalah sebuah struktur anjungan (plat form) sebagai tempat untuk meletakkan peralatan pengeboran. Dikenal dua macam anjungan, yaitu anjungan permanen (fixed) yang berdiri diatas kakikaki beton bertulang, dan anjungan tidak tetap seperti swamp barge, drilling ship (floater) dan jack up rig. 
Jackup rig ini merupakan salah satu offshore rig yang mempunyai kemampuan untuk berelevasi sesuai dengan kedalaman laut tempat dilakukan pengeboran.

Peralatan pengeboran adalah serangkaian peralatan yang disusun sedemikian rupa, sehingga menyerupai batang bor, dan seluruh peralatan ini mempunyai lubang bagian dalamnya yang memungkinkan untuk melakukan sirkulasi fluida atau mud. Bagian ujung terbawah dari rangkaian pemboran adalah pahat bor atau bit yang gunanya untuk mengorek atau menggerus batuan, sehingga lubang bor bertambah dalam. Diatas pahat bor disambung dengan beberapa buah drill colar, yaitu pipa penyambung terdalam susunan rangkaian pemboran, untuk memungkinkan pencapain kedalaman tertentu, makin dalam lubang bor makin banyak jumlah drill pipe yang dibutuhkan. Diatas drill pipe disambung dengan pipa kelly, yang bertugas meneruskan gerakan dari rotary table untuk memutar seluruh rangkaian pengeboran.

\section{DAFTAR PUSTAKA}

1. Departemen Pendidikan dan Kebudayaan, 1989, Kamus Besar Bahasa Indonesia, Jakarta.

2. Egel, Jeffrey, 1993, Kamus Istilah Teknik Perkapalan, Arikha Media Cipta, Jakarta

3. Fakultas Teknik Kelautan Institut Teknologi Sepuluh November, 1981, Kamus Istilah Perkapalan, Fakultas Teknik Kelautan Institut Teknologi Sepuluh November, Surabaya.

4. PT. Biro Klasifikasi Indonesia, 2002, Peraturan Klasifikasi dan Survey Jilid I, PT Biro Klasifikasi Indonesia, Jakarta.

5. Raswari, 1984. Teknologi dan Perencanaan Sistem Perpipaan. Universitas Indonesia Press. Jakarta. 